\title{
Correction to: Individualizing Time-in-Range Goals in Management of Diabetes Mellitus and Role of Insulin: Clinical Insights From a Multinational Panel
}

Sanjay Kalra · Shehla Shaikh · Gagan Priya · Manas P. Baruah · Abhyudaya Verma · Ashok K. Das · Mona Shah · Sambit Das · Deepak Khandelwal · Debmalya Sanyal · Sujoy Ghosh · Banshi Saboo · Ganapathi Bantwal · Usha Ayyagari · Daphne Gardner - Cecilia Jimeno · Nancy Elbarbary · Khadijah A. Hafidh · Jyoti Bhattarai · Tania T. Minulj · Hendra Zufry - Uditha Bulugahapitiya - Moosa Murad - Alexander Tan · Selim Shahjada ·

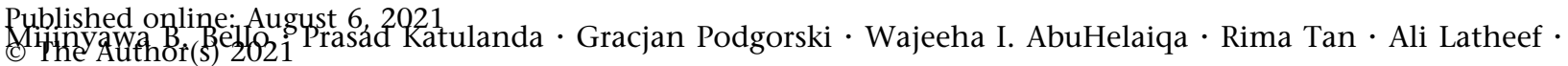
Sedeshan Govender · Samir H. Assaad-Khalil - Cecilia Kootin-Sanwu • Ansumali Joshi · Faruque Pathan •

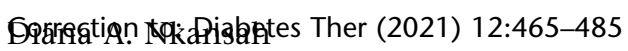
https://doi.org/10.1007/s13300-020-00973-0

In the original article, seventeenth author name published incorrectly. The correct name is Nancy Elbarbary.

The original article can be found online at https://doi. org/10.1007/s13300-020-00973-0.

S. Kalra $(\bowtie)$

Department of Endocrinology, Bharti Hospital and BRIDE, Karnal, Haryana, India

e-mail: brideknl@gmail.com

\section{S. Shaikh}

Department of Endocrinology, KGN Institute of Diabetes and Endocrinology, Mumbai, Maharashtra, India

G. Priya

Department of Endocrinology, Fortis Hospital,

Chandigarh, Punjab, India

\section{P. Baruah}

Department of Endocrinology, Excel Hospital, Guwahati, Assam, India

\section{A. Verma}

Endocrine Division, Index Medical College, Indore, Madhya Pradesh, India

\author{
A. K. Das \\ Department of Endocrinology and Medicine, \\ Pondicherry Institute of Medical Sciences, \\ Puducherry, India \\ M. Shah \\ HARMONY Endocrine Diabetes and Metabolic \\ Clinic, Vadodara, Gujarat, India \\ S. Das \\ Department of Endocrinology, Apollo Hospitals, \\ Bhubaneswar, Odisha, India \\ D. Khandelwal \\ Department of Endocrinology and Diabetes, \\ Maharaja Agrasen Hospital, New Delhi, India \\ D. Sanyal \\ Department of Endocrinology, KPC Medical \\ College, Kolkata, West Bengal, India \\ S. Ghosh \\ Department of Endocrinology and Metabolism, \\ IPGMER, Kolkata, West Bengal, India
}




\section{B. Saboo}

Dia Care, Diabetes Care and Hormone Clinic, Ahmedabad, Gujarat, India

G. Bantwal

Department of Endocrinology, St. John's Medical College and Hospital, Bangalore, Karnataka, India

\section{U. Ayyagari}

Department of Endocrinology, Apollo Sugar

Clinics, Chennai, Tamil Nadu, India

D. Gardner

Department of Endocrinology, Singapore General Hospital, Singapore, Singapore

C. Jimeno

Department of Endocrinology, Philippine Society of Endocrinology, Diabetes and Metabolism, Manila, Philippines

N. Elbarbary

Department of Endocrinology, Ain Shams

University, Cairo, Egypt

K. A. Hafidh

Department of Endocrinology, Rashid Hospital-

Dubai Health Authority, Dubai, UAE

J. Bhattarai

Department of Endocrinology, Metro Kathmandu Hospital, Kathmandu, Nepal
T. T. Minulj

Department of Endocrinology, General Hospital Karyadi, Semarang, Indonesia

H. Zufry

Department of Endocrinology, General Hospital Zainoel Abidin, Aceh, Indonesia

U. Bulugahapitiya

Department of Endocrinology, Colombo South Teaching Hospital, Colombo, Sri Lanka

\section{Murad}

Department of Internal Medicine, Indira Gandhi Memorial Hospital, Malé, Maldives

A. Tan Department of Endocrinology, Sunway Medical Centre, Kuala Lumpur, Malaysia

S. Shahjada

Department of Endocrinology, BSMMU

(Bangabandhu Sheikh Mujib Medical University Hospital), Dhaka, Bangladesh

M. B. Bello

Department of Endocrinology, Gwarinpa District Hospital, Abuja, Nigeria

P. Katulanda

Department of Endocrinology, University of Colombo, Colombo, Sri Lanka 
Open Access. This article is licensed under a Creative Commons Attribution-NonCommercial 4.0 International License, which permits any non-commercial use, sharing, adaptation, distribution and reproduction in any medium or format, as long as you give appropriate credit to the original author(s) and the source, provide a link to the Creative Commons licence, and indicate if changes were made. The images or other third party material in this article are included in the article's

G. Podgorski

Department of Endocrinology, Greenacres

Hospital, Port Elizabeth, South Africa

W. I. AbuHelaiqa

Department of Endocrinology, Hamad General

Hospital, Doha, Qatar

R. Tan

Department of Endocrinology, FEU-NRMF Medical

Center, Quezon City, Philippines

A. Latheef

Department of Endocrinology, Indira Gandhi

Memorial Hospital, Malé, Maldives

S. Govender

Umhlanga Centre for Diabetes Endocrinology,

Durban, South Africa

S. H. Assaad-Khalil

Department of Endocrinology, Alexandria

University, Alexandria, Egypt

C. Kootin-Sanwu

Department of Endocrinology, Ridge Hospital

Accra, Accra, Ghana

A. Joshi

Department of Endocrinology, Kathmandu

Diabetes and Thyroid Center, Kathmandu, Nepal
Creative Commons licence, unless indicated otherwise in a credit line to the material. If material is not included in the article's Creative Commons licence and your intended use is not permitted by statutory regulation or exceeds the permitted use, you will need to obtain permission directly from the copyright holder. To view a copy of this licence, visit http:// creativecommons.org/licenses/by-nc/4.0/.

F. Pathan

Department of Endocrinology, Bangladesh

Institute of Research and Rehabilitation for

Diabetes, Endocrine and Metabolic Disorders (BIRDEM), Dhaka, Bangladesh

D. A. Nkansah

Department of Endocrinology, 37 Military Hospital

Accra, Accra, Ghana 